\title{
Knowledge, Attitude and Practice of Community Pharmacists towards Cognitive Pharmaceutical Care Services in Tamil Nadu, India
}

M. DEEPALAKSHMI, T. DEVIPRIYA, K. P. ARUN AND S. PONNUSANKAR*

Department of Pharmacy Practice, JSS College of Pharmacy, Ooty-643 001, India

Deepalakshmi, et al.: Community Pharmacists Services in Tamil Nadu, India

The objective of this prospective cross-sectional survey was to assess the knowledge, attitude and practice of community pharmacists towards cognitive pharmaceutical care services in the state of Tamil Nadu, 
India. The self-administered survey questionnaire contained a total of 20 questions out of which, couples of questions were to assess the knowledge and 9 questions each for assessing the attitude and perception of the community pharmacists. The questionnaire was validated for the reliability and validity through a pilot survey conducted with 20 respondents prior to the full-fledged survey. Two hundred fifty six pharmacists completed the self-administered questionnaire. Data analysis was done using descriptive statistics. Less than $25 \%$ of pharmacists in this study were familiar with the term pharmaceutical care. Nearly $70 \%$ of the respondents felt that their knowledge and skills have to be further developed to equip themselves to provide pharmaceutical care services. Also, insufficient curriculum, training and lack of confidence were spelled as barriers for providing pharmaceutical care services. This revealed a mismatch between the basic pharmacy curriculum and training in India and the expected practice standards globally.

Key words: Pharmaceutical care services, community pharmacists, knowledge, attitude, perception, continuing pharmacy education, India

Pharmacy practice in general and the professional roles of the community pharmacists in particular have advanced greatly from mere dispensing of medicines to cognitive roles those are patient centred. Such changing roles demonstrated at developed countries in the late $20^{\text {th }}$ century paved the way for the philosophy of pharmaceutical care and the same had slowly invaded into the developing countries in $21^{\text {st }}$ century. The expectations of the end users of the pharmacy services on par with the standards of developed countries necessitate the provision of pharmaceutical care services irrespective of the socio-economic status of the countries.

By considering the definition of pharmaceutical care by Hepler and Strand ${ }^{[1]}$, World Health Organization $(\mathrm{WHO})^{[2]}$, stated that, 'the patient becomes the primary beneficiary by availing the pharmacist's professional roles. Such pharmaceutical services aim for accomplishing definite therapeutic outcomes in patients' health and quality of life by the virtue of knowledge, attitudes, commitments, responsibilities and skills of the pharmacists ${ }^{[3]}$.

The consultative group of $\mathrm{WHO}^{[4]}$ further expanded that the beneficiaries of the pharmaceutical care services as the general public rather than an individual patient and recognized pharmacists as active members of the health care team in preventing illness and promoting the health. Thus, the pharmacists are expected to deliver their professional services pertaining to individuals and to the community as a whole. A noteworthy recommendation of this group was that all pharmacists should aspire to provide pharmaceutical care services by considering the status of the health care delivery in their own country. Further, this group advised that the

*Address for correspondence E-mail: ponnusankarsivas@gmail.com professional roles and responsibilities of pharmacists should comply with the national pharmacy standards, if any, and Good Pharmacy Practice guidelines of International Pharmaceutical Federation (FIP) ${ }^{[5]}$.

These recommendations have acknowledged the fact that there exists a drastic difference in the status and quality of pharmaceutical care services being provided or aspired to provide in different countries across the globe ${ }^{[6]}$. But in a country like India with diverse demography of the patients, it is also not surprising to understand that such differences exist even within a country at different regions. In this background, it is imperative to motivate and prepare the pharmacists for the new set of professional standards.

However, the efforts for implementing the practice of pharmaceutical care services in community pharmacy settings have to overcome various barriers those include but not limited to basic professional education and training, economic status of the community pharmacy, inter-professional conflicts, technology limitations and even varying demands of the patients. In spite of such barriers, it is obvious that the ever increasing concerns about patient safety and quality of health care claim for the unprecedented professional roles and responsibilities of the community pharmacists even in developing countries.

In India, most of the community pharmacists do their practice with either one year or two years of diploma

This is an open access article distributed under the terms of the Creative Commons Attribution-NonCommercial-ShareAlike 3.0 License, which allows others to remix, tweak, and build upon the work non-commercially, as long as the author is credited and the new creations are licensed under the identical terms

Accepted 06 December 2016

Revised 22 October 2016

Received 03 July 2016

Indian J Pharm Sci 2016;78(6):844-849 
in pharmacy (D. Pharm) qualification with $500 \mathrm{~h}$ of training in dispensing medicines at hospitals. Even the pharmacists practicing in the community with a bachelor of pharmacy (B. Pharm) qualification hardly had any training in pharmaceutical care services as the program per se focuses industrial aspects of pharmacy rather than the practice aspects. Historically, these pharmacists are confined only to prescription filling and selling of medicines. In this background, it becomes very important to understand the present status of community pharmacists and their knowledge, attitude and perception about pharmaceutical care before attempting to encourage them for such advanced services. This will also help us to plan strategically and achieve successful implementation of pharmaceutical care services in community pharmacies.

This study was conducted as a prospective crosssectional survey using self-administered questionnaire in the state of Tamil Nadu in India. According to the Tamil Nadu Chemists and Druggists association, at the time of this survey, there were about 20000 registered pharmacists practicing in community pharmacies across 32 districts of the state of Tamil Nadu. The sampling frame consisted of licensed pharmacists practicing in community pharmacies. The sample size was calculated based on the cluster sampling method by considering the 32 districts as individual clusters and estimated percent in the target population with the event of interest as 80 (considering $20 \%$ dropouts or nonresponders), confidence interval of $\pm 5 \%$, confidence coefficient of $95 \%$ and estimated design effect of 1. The total sample size of 256 was arrived with the sample of 8 in each cluster. These 8 respondents within each cluster were selected by random and convenience sampling method.

A survey questionnaire was designed based on the objectives of the study and the perspective of the respondents. The questionnaire contained a total of 20 questions out of which couple of questions is to assess the knowledge and 9 questions each for assessing the attitude and perception of the community pharmacists. All these were closed ended questions with multiple choices as responses to be selected. As the designing of survey questions is an iterative process, both the questionnaire and introductory script were peer reviewed and the language, structure of the question, sequencing of questions were revised more than once. The questionnaire was validated for the reliability and validity through a pilot test conducted with 20 respondents prior to the full-fledged survey.
The data collected were entered into Microsoft Excel computer package for sorting, analysed with SPSS version 14. Descriptive statistics viz. frequencies, mean scores and attitudinal differences on sample characteristics were computed.

All the 256 pharmacists completed the selfadministered questionnaire. Male pharmacists more than twice as many as female pharmacists $(68 \%$; $\mathrm{n}=173$ and $32 \% ; \mathrm{n}=83$, respectively) participated in the study. The mean age of the study participants was found to be $40.04 \pm 13.9$ and majority of the pharmacists $(n=173)$ were in the age group of 31 to 50 years. Diploma in pharmacy (D. Pharm), which is the minimum qualification for a registered pharmacist in India was found to be the qualification of majority of the respondents $(n=210 ; 82 \%)$ followed by bachelor of pharmacy (B. Pharm; $n=46 ; 18 \%$ ). Sixty four percent $(n=165)$ of the respondents were known to have 5 to $20 \mathrm{y}$ of professional experience in the community of pharmacy. The demographic data of the study participants are presented in Table 1 .

Only about $22 \%(n=56)$ of the respondents were familiar with the term pharmaceutical care and nearly $42 \%(n=107)$ of the pharmacists were aware about services provided by community pharmacists at developed countries (fig. 1). These revealed that though there was some knowledge about the names of various pharmaceutical care services, the study participants were not aware of those services under the term 'Pharmaceutical Care'. Thus, it is understood that the community pharmacists participated in this study were having less knowledge and lack of general idea about the concept of pharmaceutical care.

Nearly $30 \%(n=75)$ of the pharmacists said that the

TABLE 1: DEMOGRAPHIC DETAILS OF THE STUDY PARTICIPANTS

\begin{tabular}{lc}
\hline Gender; N (\%) & Male; $173(68)$ \\
& Female; $83(32)$ \\
Age (y); N (\%) & $21-30 ; 40(16)$ \\
& $31-40 ; 104(41)$ \\
& $41-50 ; 69(27)$ \\
& $51-60 ; 11(27)$ \\
& $>60 ; 16(6)$ \\
& Mean: 40.04 13.9 \\
Qualification; N (\%) & D.Pharm.; $210(82)$ \\
& B.Pharm.; 46 (18) \\
Professional experience & $<5 ; 41(16)$ \\
(in y); N (\%) & $5-10 ; 91(36)$ \\
& $11-20 ; 74(29)$ \\
& $>20 ; 50(19)$ \\
\hline
\end{tabular}




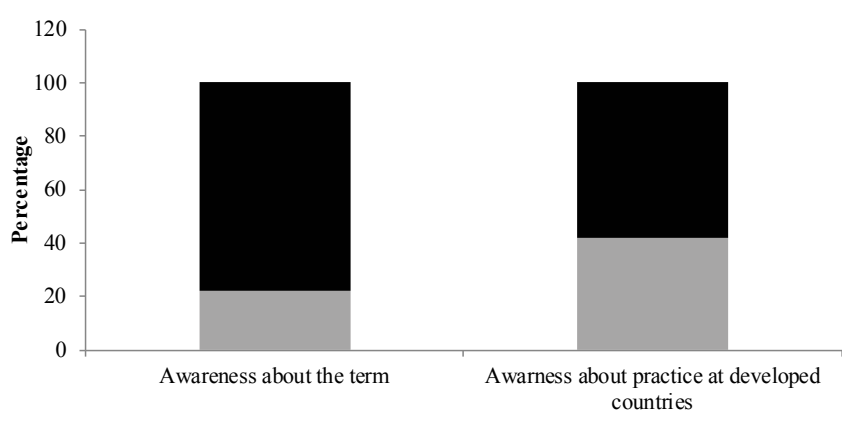

Fig. 1: Basic knowledge about pharmaceutical care services.

- No; - Yes

profession was opted by their choice followed by $23 \%$ $(n=59)$ who entered into the profession so as to continue their family business of retail pharmacy outlets. Exactly $50 \%$ of the pharmacists $(n=128)$ revealed their interest to enhance their knowledge and skills through continuing professional education (CPE) programs while the remaining $49 \%(n=125)$ did not have the attitude to do so. Nearly three fourth $(74 \% ; n=189)$ of the respondents interested towards CPE were aspiring to do their higher education in the 'Pharmacy Practice' area followed by 'Marketing and Management' (18\%; $\mathrm{n}=46)$ and 'Pharmaceutical Sciences' $(8 \% ; n=21)$.

About 176 respondents (69\%) showed the attitude of providing pharmaceutical care services provided if their knowledge and skills about such services improved while only $13 \%(n=33)$ were ready to provide pharmaceutical care services with their present level of education and training and about $18 \%(n=46)$ refused to provide any such services in their community pharmacy. About $78 \%(\mathrm{n}=200)$ of the pharmacists had a perception that dispensing the medicines as per the prescription is their only responsibility. Majority of the respondents $(67 \% ; n=172)$ opined that provision of pharmaceutical care in community pharmacies would certainly enhance the confidence of the patients on pharmacists and pharmacy profession. 63\% $(\mathrm{n}=161)$ and $27 \%$ $(n=69)$ of the respondents expressed that the pharmacy curriculum and training did not develop the skills required for providing pharmaceutical care services and the lack of self-confidence are the most important barriers in implementing such services in community pharmacies. About 64\% $(n=164)$ respondents readily agreed to undergo training to upgrade their knowledge and skills in pharmaceutical care services in the present scenario. Out of these respondents, nearly 33\% each $(n=55)$ had opted health screening, adverse drug reaction monitoring and immunization as their first three choices to implement in their practice. Among the remaining who were not positive about undergoing such training programs at present $(36 \% ; n=92)$, lack of motivation/interest and lack of time were the primary reasons said $(67 \% ; n=62$ and $33 \% ; n=30$, respectively). About 56\% ( $\mathrm{n}=143)$ had the perception that improving the knowledge of the practicing pharmacists would only improve the standards of community pharmacy practice followed by more interaction between pharmacists and patients $(32 \% ; n=82)$. About $85 \%$ $(n=218)$ of the respondents expressed that they were satisfied with their profession. About $82 \%(n=210)$ of the pharmacists agreed that they never tried to provide pharmaceutical care and $17 \%(n=43)$ said they tried sometimes while only the remaining $1 \%(n=3)$ said they always provide pharmaceutical care (fig. 2). Nearly two third $64 \%(n=163)$ of the community pharmacists participated in this study had the practice of either rarely double check the prescription against dispensed medicines $(32 \% ; n=83)$ or never did such exercise $(31 \% ; n=80)$. Nearly half of the pharmacists $(43 \% ; n=111)$ had been spending less than 5 min with patients while their prescriptions were filled. Another $38 \%(n=96)$ tend to spend 5 to 10 min while the others claimed more than $15 \mathrm{~min}$. Nearly two third of the pharmacists $(73 \% ; n=188)$ never had the practice of contacting the prescriber for any reason. About $10 \%$ of the pharmacists said that they did contact either once in a week or once in a month for prescription-related issues.

Less than one among four practicing pharmacists has been found to be familiar with the term pharmaceutical care. This is not very surprising because, more than $80 \%$ of the practicing pharmacists were qualified with a diploma in pharmacy and the concept of 'Pharmaceutical Care' has never been a part of their curriculum. This is concordant with the results of the study ${ }^{[7]}$ conducted at Kaduna state, Nigeria, which showed $97.5 \%$ of respondents had knowledge deficit of pharmaceutical care concepts. It is interesting to note that the percentage of respondents' awareness about services provided by community pharmacists in developed countries was more (42\%) than those who knew the term 'Pharmaceutical Care Services' $(22 \%)$. This contradiction revealed that even though the respondents of this study knew a few names of the pharmaceutical care services provided by the pharmacists in developed countries, they do not know the professional dimensions of such services.

Only one third of the respondents chose pharmacy as a career by their choice and the rest two third of them were in the profession only by a chance. Similar 


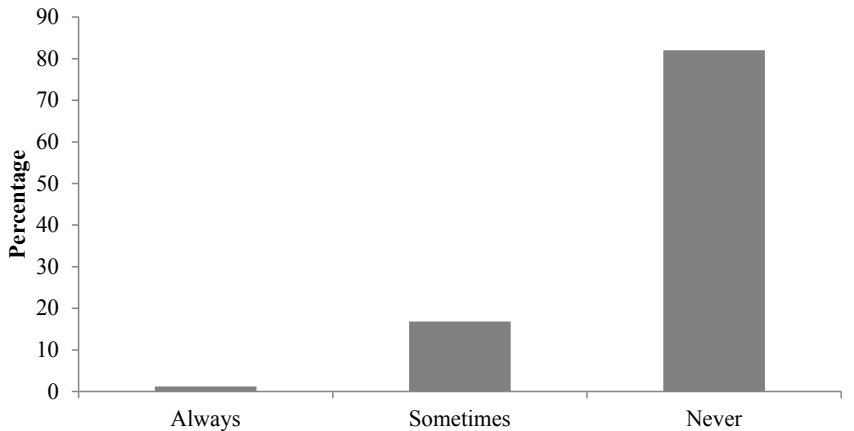

Fig. 2: Current status of pharmaceutical care services at community pharmacy set-up.

observations were found in a study ${ }^{[8]}$ done among the graduating students in Jordan which reported that for $61 \%$ of students, pharmacy was not the first career choice before they joined the universities. At least half of the respondents were found motivated to attend the continuing professional education programs as that of the reported study ${ }^{[9]}$ in which the pharmacists valued the continuing professional education for professional growth and licensure requirements. Nearly $69 \%$ of the respondents felt that their knowledge and skills are to be further developed to equip themselves to provide pharmaceutical care services. This is very much consistent with the results of the study reported by Basak et al. in 2005 who reported that $67.5 \%$ of community pharmacists felt that existing knowledge was not sufficient to provide health care services ${ }^{[10]}$. It is alarming to note that between 2005 and 2016, for more than a decade, this status of community pharmacists in the state of Tamil Nadu in South India did not improve in this aspect. Also, the inadequate curriculum, training and lack of confidence were cited as barriers for providing pharmaceutical care services. This revealed an existing mismatch between the pharmacy curriculum, training in India and the expected global practice standards. A study conducted among Eritrean pharmacists also indicated that nearly $86 \%$ of those participated in the study felt such mismatch and wanted to redefine the current roles and responsibilities towards pharmaceutical care ${ }^{[11]}$. Another study conducted in $\mathrm{UAE}^{[12]}$ had reported that lack of motivation accounted for about $61 \%$ as a barrier for providing pharmaceutical care services in the community pharmacy. A study conducted at Jordan reported $^{[13]}$ lack of training on pharmaceutical care as the top barrier for the provision of pharmaceutical care.

Only a negligible percentage of pharmacists said that they always provided pharmaceutical care and the subset analysis of the data revealed that these pharmacists work in chain pharmacies wherein the top management mandate such patient care services. It was also understood that the pharmacists spent less than $5 \mathrm{~min}$ to fill each prescription and mostly these prescriptions are not double checked before dispensing.

The present practice of pharmacy in the community set-up needs improvement with respect to shift from product-oriented to patient-oriented services. A systematic review ${ }^{[14]}$ by Basak et al. also concluded that the healthcare services in community pharmacies was insignificant and must undergo reforms to meet the changing needs of modern medicine users. The provision of pharmaceutical care services in the community pharmacies is not common in India and limited only to a few chain pharmacies. Lack of knowledge about pharmaceutical care and adequate training in this area have been the biggest barriers for not providing such specialized services to the patient community. Most of the pharmacists expressed their willingness to participate in continuing professional education program to update and upgrade their knowledge and skills related to pharmaceutical care services. In this context, a well-structured continuing professional education programs should be organized with adequate credit hours and these credit points should be considered for their licensure renewal. Indian pharmaceutical regulators and academic institution should make sincere efforts to conduct authenticated continuing education programs for the community pharmacists, if the present status is to be improved.

\section{Acknowledgement:}

The authors acknowledge the JSS University, Mysore for granting permission for the conduct of this work as a part of a Ph.D. dissertation of one of the faculty members.

\section{Financial support and sponsorship:}

Nil.

\section{Conflicts of interest:}

There are no conflicts of interest.

\section{REFERENCES}

1. Hepler CD, Strand LM. Opportunities and responsibilities in pharmaceutical care. Am J Hosp Pharm 1990;47:533-43.

2. WHO. Handbook of Resolutions and Decisions of the World Health Assembly and Executive Board. 11th ed. World Health Organization: Geneva; 1972.

3. Alexandria VA. Commission to Implement Change in Pharmaceutical Education. A position paper Entry-level 
Education in Pharmacy: A Commitment to Change. American Association of Colleges of Pharmacy News. Special Report; 1991.

4. http://apps.who.int/iris/handle/10665/61679.

5. International Pharmaceutical Federation. Statement on Pharmaceutical Care; 1998.

6. Farris KB, Llimos FF, Benrimoj S. Pharmaceutical Care in Community Pharmacies: Practice and Research from Around the World. Ann Pharmacother 2005;39:1539-41.

7. Hadiza U, Ondeku SI. Assessment of knowledge, attitude and practice of community pharmacists towards pharmaceutical care in Konduna state of Nigeria. Int $\mathrm{J}$ Pharm Teaching Practice 2014;5:972-6.

8. Mukattash TL, Nuseir KQ, Biltaji E, Jarab AS, Alefan Q. Students perceptions of pharmacy as a specialization and their future career, a cross sectional study of final year pharmacy students in Jordan. Jordan J Pharm Sci 2015;8:195.

9. Roderick S, Arianne DA. An assessment of the training needs and preferred course formats for continuing professional education of Filipino pharmacists. Int $\mathrm{J}$ Pharm Teaching Practice 2014;5:867-73.

10. Basak SC, Prasad GS, Arunkumar A, Senthilkumar S. An attempt to develop community pharmacy practice: Results of two surveys and two workshops conducted in Tamilnadu. Indian J Pharm Sci 2005;67:362-7.

11. Awalom MT, Tesfa AF, Kidane ME, Eritrean. Pharmacists' job satisfaction and their attitude to re-professionalize pharmacy in to pharmaceutical care. Int J Clin Pharm 2015;37:335-41.

12. Ghazal RM, Hassan NAG, Ghaleb O, Ahdab Al, Saliem II. Barriers to the implementation of Pharmaceutical Care into the UAE community pharmacies. IOSR J Pharm 2014;4:68-74.

13. AbuRuz SM, Al-Ghazawi MA, Bulatova N, Jarab AS, Alawwa IA, Al Saleh A. Expectations and experiences of physicians regarding pharmaceutical care and the expanding role of pharmacists. J Pharm Pharm Sci 2012;5:2768.

14. Basak SC, Van Mil JWF, Sathyanarayan D. The changing roles of pharmacists in community pharmacies: perception of reality in India. Pharm World Sci 2009;31:612-18. 